\title{
Craniotomy for perisellar meningiomas: comparison of simple (appropriate for endoscopic approach) versus complex anatomy and surgical outcomes
}

\author{
Serge Makarenko, MD, Erick M. Carreras, BSc, and Ryojo Akagami, MD, MHSc, FRCSC \\ Department of Surgery, Vancouver General Hospital, University of British Columbia, Vancouver, British Columbia, Canada
}

OBJECTIVE Microsurgical resection of perisellar meningiomas has remained the gold standard for treatment, with extended endoscopic endonasal surgery emerging as a viable alternative. Historical microsurgical series do not distinguish based on tumor anatomy, but are being used as a comparison against endonasal surgery. In this study, the authors retrospectively reviewed and compared the anatomy of perisellar meningiomas seen at their institution. The tumors were separated into 2 groups based on whether they would be appropriate for endoscopic resection, and the authors compared the surgical outcomes.

METHODS Between 2001 and 2013, 53 patients (73.6\% women) with perisellar meningiomas underwent open microsurgical resection at Vancouver General Hospital performed by the senior author (R.A.). These tumors were separated into 2 groups based on their anatomy, and the authors analyzed the resection rates, surgical results, patient quality of life, and complications.

RESULTS Among the 53 patients who presented with perisellar meningiomas, the authors were able to identify 18 lesions with "simple" anatomy suitable for endoscopic resection and 35 lesions with "complex" anatomy suitable for craniotomy resection. The mean age of patients in the study cohort was 57.4 years (range 33-91 years), and most patients presented with visual loss $(68.0 \%)$ and visual field restriction $(64.2 \%)$. There were no major differences in patient demographic data between the 2 groups. Patients with simple anatomy had smaller lesions ( $2.1 \mathrm{vs} 3.5 \mathrm{~cm} ; p=0.004)$, no optic canal invasion ( $89 \%$ vs $26 \% ; p<0.0001$ ), minimal vascular encasement (cortical cuff $83 \%$ vs $9 \% ; p<0.0001$ ), and a rounded tumor shape $(100 \%$ vs $31.8 \% ; p=0.0001)$ when compared with those with complex anatomy. The majority of lesions originated from the tuberculum sellae and planum sphenoidale. A greater degree of resection was achieved in the favorable anatomy group ( $99 \%$ vs $87.1 \% ; p<0.0001)$. Vision was improved or normalized in $96.6 \%$ of patients. Patients in the cohort with complex anatomy had more transient complications; there were no incidents of surgical-site infection, meningitis, or death in this series. One patient who underwent removal of a recurrent lesion experienced a CSF leak that required endoscopic repair. The overall persisting complications rate was higher in the group with complex anatomy $(11.1 \%$ vs $37.1 \% ; p=0.0498)$; overall, $28.3 \%$ of patients experienced disabling complications. Patient-perceived quality of life improved in the simple anatomy group following surgery ( $\Delta$ SF-36 +16.6 vs $-8.4 ; p=0.0045)$.

CONCLUSIONS Extended endoscopic surgery is emerging as a viable alternative to microsurgical resection of perisellar meningiomas. The authors identified 2 patient groups based on tumor anatomy, with distinctly separate surgical outcomes. In the future, patients considered for endoscopic resection should be compared against the surgical group with simple anatomy that includes smaller tumors, no vascular encasement, and limited optic canal invasion.

https://thejns.org/doi/abs/10.3171/2016.3.JNS152307

KEY WORDS perisellar meningioma; anatomy; craniotomy; skull base; endoscopic surgery; oncology

$\mathrm{T}$ HE treatment of intracranial perisellar meningiomas has remained a significant challenge over the past several decades. Representing $5 \%-10 \%$ of all intracranial meningiomas, the difficulty with resection has been mainly attributed to the high risk of visual pathway involvement, cavernous sinus infiltration, vascular encasement, and pituitary apparatus involvement. ${ }^{15,16}$ In addition, significant morbidity and mortality associated with the craniotomy have increased the difficulty in attempts at gross-total resection (GTR) of these lesions. As such,

ABBREVIATIONS FIESTA = fast imaging employing steady-state acquisition; GTR = gross-total resection; QoL = quality of life; SF-36 = 36-ltem Short-Form Health Survey. SUBMITTED October 6, 2015. ACCEPTED March 8, 2016.

INCLUDE WHEN CITING Published online June 10, 2016; DOI: 10.3171/2016.3.JNS152307. 
even by best estimates, complication rates have ranged from $32 \%$ to $61 \%$ in published studies. . $^{6,7,12,14,21-24}$ These lesions arise from the tuberculum sellae, diaphragma sellae, chiasmatic sulcus, and limbus sphenoidalis. Surgical approaches are the mainstay of definitive treatment, with subfrontal, pterional, frontolateral, and orbitofrontal variants most commonly used; the goals are preservation of visual function and sensation of smell, while achieving GTR.

More recently, extended endoscopic transsphenoidal surgery has been emerging as an alternative option for treatment of these lesions in the armamentarium of the skull base surgeon. ${ }^{7-9}$ Endoscopic transsphenoidal surgery provides panoramic visualization and a wide access to the anterior skull base, with advances such as angled endoscopes and image guidance increasing success rates of the novel approach while preserving visual function. A perceived increase in patient comfort and a decrease in complications and length of hospital stay further boost the attractiveness of this approach. ${ }^{19}$ Several authors claim that most suprasellar meningiomas-regardless of their location, extension, and optic nerve/optic canal involvementcan be removed with extended endoscopic surgery.18,19,26 Despite this, there are no clearly established characteristics of the tumors that would be appropriate for this treatment, and the decision is frequently left to the discretion of the neurosurgeon. Previous series do not distinguish based on tumor anatomy. As the use of the endoscopic technique for removal of these tumors becomes more widespread, a selection bias based on anatomy is difficult to avoid.

We report a surgical series of 53 meningiomas arising from the perisellar region that were surgically removed in a single neurosurgical institution between 2001 and 2013 by the senior author (R.A.). We characterize the anatomy of the individual tumors and separate them into 2 groups based on "simple" and "complex" anatomy; in our opinion, the former is favorable for an endoscopic approach. Our results from the approach in the era of advanced microsurgery are presented, focusing on tumor control, long-term visual function, and complications compared between the 2 groups. We provide an analysis of surgical outcomes and recurrence rates according to the anatomy as determined by the authors, to allow for the creation of a surgical series that can be used as a gold standard for comparison with future endoscopic cases in our institution and elsewhere, and to minimize the selection bias.

\section{Methods}

This study was approved by the Clinical Research Ethics Board of the University of British Columbia.

We undertook a retrospective review of the neurosurgical database at the Vancouver General Hospital, identifying patients diagnosed with perisellar meningiomas between January 1, 2001, and December 31, 2013. A careful review of clinical records and radiological analysis was made. All patients were evaluated by a neuroophthalmologist before and after surgery, with thorough assessment of visual acuity and visual fields.

Microsurgical resection of the tumor was performed via a frontotemporal craniotomy with orbital osteotomy; the procedure was unilateral depending on the side with worse vision as determined preoperatively by a thorough neuroophthalmological evaluation. ${ }^{4}$ An extradural decompression of the optic canal and resection of the clinoid was performed prior to the removal of tumor in all cases. In 19 patients, GTR was not the goal due to the tumor size and extensive structural involvement. Postoperatively, the patients were transferred to the neurocritical monitoring unit for frequent neurological monitoring and observation, and subsequently were discharged after satisfactory mobilization and adequate normalization of bloodwork.

The breakdown of the patients with perisellar meningiomas into groups with simple and complex anatomy was determined on a case-by-case basis by the authors, prior to reviewing the clinical outcome. Imaging characteristics were analyzed for each patient, and a decision was made based on lesion size, vascular encasement, lateral extension, and tumor shape. Encasement was defined as visible tumor tissue $>180^{\circ}$ around a major vascular structure within the circle of Willis (primarily the anterior cerebral artery, middle cerebral artery, internal carotid artery, and their associated perforating vessels). Optic canal involvement was also assessed on coronal MRI. All imaging interpretations by the senior author were compared and verified against those of an experienced neuroradiologist at our institution.

Significant lateral extension was noted for those lesions extending beyond the optic canal unilaterally or bilaterally. In our series, superior extension was not involved as a factor determining degree of anatomical complexity unless vascular encasement was encountered. Those lesions with significant posterior extension into the posterior fossa were not included in our study. Additionally, some surgeons consider edema as a predictor of poor surgical planes intraoperatively, and as such that it would increase the difficulty level of resection. In our cases, it was not seen as a significant factor for the purpose of stratification.

Those lesions that were thought to be easily accessible through an endoscopic approach were designated as "simple" anatomy. The lesions that included significant lateral extension, or those tumors that had extensive vascular encasement as defined above, were deemed more suitable for open resection and were designated as "complex" anatomy. We compared our designations against those found in the literature and found adequate consensus among authors regarding which lesions would be suitable for an endoscopic approach., ${ }^{7,1926}$ To assess patient-reported evaluations of their own health, we collected 36-Item ShortForm Health Survey (SF-36) data where available. ${ }^{27}$

\section{Statistical Analysis}

The patient demographic data, clinical presentation, tumor imaging characteristics, surgical approaches, and postoperative outcomes were analyzed using descriptive statistics. The GTR and extent of resection rates for every studied tumor were compared. A p value $<0.05$ was considered statistically significant. Data were collected using Microsoft Excel 2010, and all variables were tested for an association with either a simple or complex anatomy. Categorical variables were tested using a chi-square test. When variables did not meet the assumptions of minimum 
expected frequencies required by the chi-square test, Fisher's exact tests were conducted. The Benjamini-Hochberg procedure was implemented to ensure a false discovery rate no higher than 5\% among the multiple comparison tests performed. ${ }^{3,13}$ Continuous data were tested for a nonnormal distribution using the Shapiro-Wilk test. A Student t-test was performed on normally distributed data, and the Wilcoxon rank-sum test was conducted on statistically significant non-normally distributed data. The statistical analyses were conducted using JMP version 9.0.1 for Mac (SAS Institute, Inc.).

\section{Results}

\section{Patient Population}

Fifty-three patients with perisellar meningiomas originating from the tuberculum sellae and/or planum sphenoidale were identified. Forty meningiomas included in this study were benign (WHO Grade I), and 13 were WHO Grade II. The mean age of patients was 57.4 years (range 33-91 years), and there was a clear predominance of women (73.6\%). Of the patients included in this study, 44 had primary tumors $(83.0 \%), 5$ had undergone a previous craniotomy at the same center performed by a different surgeon $(9.4 \%)$, and 4 had a previous craniotomy and radiation therapy (7.5\%). The symptom duration ranged from 1 to 60 months (average 16.2 months) (Table 1).

We were able to identify 18 patients with lesions that had simple anatomy (i.e., favorable for endoscopic resection) and 35 with complex anatomy (i.e., favorable for a craniotomy). Table 1 summarizes the demographic data of the patient population. There was no significant difference in these baseline characteristics between the simple and complex cohorts.

\section{Clinical Presentation}

The majority of the patients presented with visual impairment that included visual loss $(68.0 \%)$ and visual field restriction (64.2\%), and 27 patients presented with a headache $(50.9 \%)$. Nine patients presented with cranial nerve dysfunction (17.0\%), and 4 patients had anosmia (7.5\%). Change in mental status occurred in 8 patients $(15.1 \%)$, and 4 patients with tuberculum sellae meningiomas that

TABLE 1. Baseline characteristics of 53 patients who presented with perisellar meningiomas

\begin{tabular}{lccc}
\hline \multicolumn{1}{c}{ Baseline Characteristics } & $\begin{array}{c}\text { Simple } \\
\text { Anatomy }\end{array}$ & $\begin{array}{c}\text { Complex } \\
\text { Anatomy }\end{array}$ & p Value \\
\hline No. of pts & 18 & 35 & \\
\hline No. of women & 16 & 23 & 0.0699 \\
\hline Age, yrs & & & \\
\hline$\quad$ Mean & 57.0 & 57.6 & 0.4312 \\
\hline$\quad$ Range & $35-88$ & $33-91$ & \\
\hline Duration of symptoms, mos & & & \\
$\quad$ Median & 14.6 & 17.1 & 0.2764 \\
\hline$\quad$ Range & $2-60$ & $1-60$ & \\
\hline Previous craniotomy, no. of pts & 3 & 6 & 0.1961 \\
\hline Pts = patients. & & & \\
&
\end{tabular}

extended into and occupied the pituitary fossa presented with panhypopituitarism (7.5\%). Dysfunction in cranial nerves was the only significant difference between the 2 groups $(\mathrm{p}=0.0182)$. In Table 2 , clinical presentations are categorized accordingly and broken down with respect to tumor anatomy suitability for endoscopic resection.

\section{Imaging Findings}

Preoperative MRI studies were available for all patients, including fast imaging employing steady-state acquisition (FIESTA) sequences to delineate tumor anatomy in relationship to cranial nerves. Variable tumor sizes, configurations, and patterns of extension were seen. Tumor sizes varied from 0.8 to $6.6 \mathrm{~cm}$. The average maximal diameter on coronal views was $3.01 \mathrm{~cm}$ (range $0.8-6.6 \mathrm{~cm}$ ) for all lesions. The maximal coronal diameter was smaller in the group with favorable anatomy ( $2.1 \mathrm{vs} 3.5 \mathrm{~cm} ; \mathrm{p}=0.004)$. Patients with simple anatomy had lesions primarily originating in the tuberculum sellae, albeit a higher proportion than those with complex anatomy (16 cases [89\%] vs 18 cases [51\%]). Meningiomas with complex anatomy had more extension into both the tuberculum sellae and planum sphenoidale. Overall, most of the meningiomas originated from the tuberculum sellae (34 cases, 64.2\%) and the planum sphenoidale (11 cases, 20.8\%) (Table 3).

This anatomy was studied on fine-cut axial T1-weighted, postcontrast MRI, as well as FIESTA-sequence MRI when available. Vascular encasement was studied on both MRI and fine-cut CT angiography when available. Lack of optic canal invasion was one factor that played heavily into determining whether a lesion would be accessible for endoscopic resection, because the superior border of the canal is thought to be a relative contraindication to endoscopic resection.

As expected, a significantly greater proportion of participants from the favorable anatomy group had no optic canal invasion (89\% vs 26\%; $\mathrm{p}<0.0001$ ), whereas the opposite was true of unilateral optic canal invasion (11\% vs $51 \% ; p=0.0008$ ). Similarly, a greater proportion of participants from the complex anatomy group had bilateral optic canal invasion ( $0 \%$ vs $23 \%$; $p=0.1436)$. Minimal vascular encasement was also more apparent in the favorable anat-

TABLE 2. Clinical presentation of 53 patients with perisellar meningiomas*

\begin{tabular}{lccc}
\hline \multicolumn{1}{c}{ Clinical Presentation } & $\begin{array}{c}\text { Simple } \\
\text { Anatomy }\end{array}$ & $\begin{array}{c}\text { Complex } \\
\text { Anatomy }\end{array}$ & p Value \\
\hline Symptom & & & \\
\hline Visual loss & $10(56.0)$ & $26(74.3)$ & 0.1665 \\
\hline Visual field restriction & $9(50.0)$ & $25(71.4)$ & 0.1234 \\
\hline Headache & $8(44.4)$ & $19(54.3)$ & 0.6300 \\
\hline Cranial nerve dysfunction & $0(0.0)$ & $9(25.7)$ & 0.0182 \\
\hline Seizures & $1(5.6)$ & $4(11.4)$ & 0.6510 \\
\hline Change in mental status & $3(16.7)$ & $5(14.3)$ & 0.8186 \\
\hline Motor/sensory deficit & $2(11.1)$ & $6(17.1)$ & 0.5613 \\
\hline Anosmia & $3(16.7)$ & $1(2.9)$ & 0.0715 \\
\hline Panhypopituitarism & $0(0.0)$ & $4(11.4)$ & 0.2868 \\
\hline *
\end{tabular}

* Values are presented as the number of patients (\%). 
TABLE 3. Imaging characteristics in 53 patients presenting with perisellar meningiomas*

\begin{tabular}{|c|c|c|c|}
\hline Imaging Findings & $\begin{array}{c}\text { Simple } \\
\text { Anatomy }\end{array}$ & $\begin{array}{l}\text { Complex } \\
\text { Anatomy }\end{array}$ & p Value \\
\hline \multicolumn{4}{|l|}{ Location } \\
\hline Tuberculum sellae & $16(88.9)$ & $18(51.4)$ & 0.0077 \\
\hline Planum/tuberculum & $1(5.6)$ & $7(20.0)$ & 0.0748 \\
\hline Planum sphenoidale & $1(5.6)$ & $10(28.6)$ & 0.0748 \\
\hline \multicolumn{4}{|l|}{ Optic canal invasion } \\
\hline None & $16(88.9)$ & $9(25.7)$ & $<0.0001 \dagger$ \\
\hline Unilateral & $2(11.1)$ & $18(51.4)$ & $0.0008 \dagger$ \\
\hline Bilateral & $0(0.0)$ & $8(22.9)$ & 0.1436 \\
\hline \multicolumn{4}{|l|}{ Vascular involvement } \\
\hline Cortical cuff & $15(83.3)$ & $3(8.6)$ & $<0.0001 \uparrow$ \\
\hline Contact & $3(16.7)$ & $1(2.9)$ & 0.1080 \\
\hline Encasement & $0(0.0)$ & $31(88.6)$ & $<0.0001 \dagger$ \\
\hline \multicolumn{4}{|l|}{ Tumor shape } \\
\hline Rounded & $18(100)$ & $11(31.4)$ & $<0.0001 \uparrow$ \\
\hline Multilobular & $0(0.0)$ & $24(68.6)$ & $<0.0001 \dagger$ \\
\hline Sella turcica invasion & $4(22.2)$ & $25(71.4)$ & 0.0007 \\
\hline Hyperostosis & $2(11.1)$ & $14(40.0)$ & 0.0300 \\
\hline $\begin{array}{l}\text { Average maximal coronal } \\
\text { diameter, } \mathrm{cm}\end{array}$ & $2.1 \pm 1.3 \ddagger$ & $3.5 \pm 1.0 \ddagger$ & 0.004 \\
\hline Extent of resection & $99.9 \%$ & $87.1 \%$ & $<0.0001$ \\
\hline GTR & $94.4 \%$ & $54.3 \%$ & $<0.0001$ \\
\hline
\end{tabular}

omy group. Those patients who had a cortical cuff (brain parenchyma between tumor and blood vessels) (83\% vs $9 \% ; \mathrm{p}<0.0001)$ or contact with vasculature $(17 \%$ vs $3 \% ; \mathrm{p}$ $=0.1080$ ) were more likely to have favorable anatomy. Meningiomas that were encasing cerebral blood supply ( $0 \%$ vs $89 \%$; $p<0.0001$ ) were considered more appropriate for resection via a craniotomy.

The perisellar meningiomas with a rounded shape ( $100 \%$ vs $31.8 \% ; \mathrm{p}=0.0001)$ versus a multilobular shape ( $0 \%$ vs $68.2 \%$; $p=0.0001$ ) were more likely to be lesions with simple anatomy. The lesions with simple anatomy were also less likely to invade the sella $(\mathrm{p}=0.0007)$, and no associated bony hyperostosis is seen on fine-cut axial CT imaging ( $\mathrm{p}=0.0300)$. Table 3 summarizes the imaging findings in perisellar meningiomas.

The length of follow-up was evaluated based on the most recent MRI session obtained. The average follow-up for the cohort was 37.3 months (range 10-120 months), without significant difference between the groups.

\section{Evaluation of Surgical Results}

Clinical outcomes after surgery were assessed by postoperative visual tests (visual acuity and visual field tests performed by an experienced neuroophthalmologist), clinical examination, and endocrine studies where indicated.

The degree of tumor resection was evaluated on postoperative MRI sequences available in every patient with 3-month postoperative MRI. The volume of residual tumor was measured using the mathematical formula of modified ellipsoid volume [( $\mathrm{A} \times \mathrm{B} \times \mathrm{C}) / 2$ ], where $\mathrm{A}, \mathrm{B}$, and $\mathrm{C}$ were the maximum diameters of the lesion in each of the 3 dimensions. The extent of resection was classified in comparison with the preoperative tumor volume as a ratio. Although GTR was not the goal of surgery in 19 patients, these patients were included in the study and were analyzed using the same criteria to avoid selection bias. Gross-total resection was established by the senior surgeon at the time of the operation and confirmed by neuroradiology on the first follow-up MRI scan at 3 months. The GTR was $94.4 \%$ in the simple anatomy group versus $54.3 \%$ in the complex anatomy group $(\mathrm{p}<0.0001)$, with an overall GTR of $67.9 \%$ among the study sample. To further quantify tumor volume resection, we saw a greater extent of resection achieved in the simple anatomy group than in the complex anatomy group (99\% vs $87.1 \%$; $p<0.0001)$, and an overall extent of resection of $91.4 \%$ (Table 3 ).

\section{Postoperative Complications}

During the short-term follow-up of 6 months, the majority of patients with tumor anatomy suitable for endoscopic resection experienced improvement or stabilization of their visual field loss, visual field restriction, and headaches. Those patients with anatomically complex lesions had transient worsening of similar symptoms, and a smaller proportion experienced improvements (Table 4).

Visual deterioration (37.7\%), neurological worsening $(26.4 \%)$, and new postoperative cranial nerve palsy (26.3\%) were the most common complications following craniotomy resection of perisellar meningiomas at our

TABLE 4. Early clinical outcomes at 6 months after microsurgical resection of 53 perisellar meningiomas*

\begin{tabular}{|c|c|c|c|c|}
\hline Initial Deficit & $\begin{array}{c}\text { No. of } \\
\text { Pts }\end{array}$ & Improved & Worsened & Unchanged \\
\hline \multicolumn{5}{|l|}{ Visual loss } \\
\hline Simple anatomy & 10 & $7(70.0)$ & $1(10.0)$ & $2(20.0)$ \\
\hline Complex anatomy & 26 & $7(26.9)$ & $10(38.5)$ & $9(34.6)$ \\
\hline \multicolumn{5}{|l|}{ Visual field restriction } \\
\hline Simple anatomy & 9 & $7(77.7)$ & $1(11.1)$ & $1(11.1)$ \\
\hline Complex anatomy & 25 & $8(32.0)$ & $9(36.0)$ & $8(32.0)$ \\
\hline \multicolumn{5}{|l|}{ Headache } \\
\hline Simple anatomy & 8 & $6(75.0)$ & $1(12.5)$ & $1(12.5)$ \\
\hline Complex anatomy & 19 & $9(47.4)$ & $10(52.6)$ & $0(0.0)$ \\
\hline \multicolumn{5}{|l|}{ Change in mental status } \\
\hline Simple anatomy & 3 & $3(100)$ & $0(0.0)$ & $0(0.0)$ \\
\hline Complex anatomy & 5 & $1(20.0)$ & $4(80.0)$ & $0(0.0)$ \\
\hline \multicolumn{5}{|l|}{ Anosmia } \\
\hline Simple anatomy & 3 & $0(0.0)$ & $0(0.0)$ & $3(100)$ \\
\hline Complex anatomy & 1 & $0(0.0)$ & $0(0.0)$ & $1(100)$ \\
\hline \multicolumn{5}{|l|}{ Seizures } \\
\hline Simple anatomy & 0 & & & \\
\hline Complex anatomy & 4 & $0(0.0)$ & $2(50.0)$ & $2(50.0)$ \\
\hline
\end{tabular}


institution. The patient cohort with the complex tumor anatomy had significantly more of these complications but only during the time period from the immediate postoperative period to the first follow-up appointment at 6 weeks (Table 5). The majority of these were transient effects that resolved within the 1st year following the craniotomy. There were no differences between the 2 patient populations in postoperative incidence of seizures, endocrinological disturbances, infarcts, or Heubner artery injuries. There was no incidence of any postoperative surgical-site infection or meningitis. There were no deaths in our series. Significantly more patients had a change in mental status postoperatively if they had complex tumor anatomy ( $0 \%$ vs $17.1 \%$; $p=0.0436$ ). One patient, who had been allocated to the favorable anatomy group, experienced a CSF leak several days after the craniotomy. This was a recurrent lesion that had been surgically treated 6 years prior, and this patient required a repeat return to the operating theater for endonasal repair of the CSF leak. All except 1 of the 53 patients in our cohort had their sense of smell

TABLE 5. All clinical outcomes investigated following microsurgical resection of 53 perisellar meningiomas*

\begin{tabular}{|c|c|c|c|c|}
\hline Complication & $\begin{array}{l}\text { No. of } \\
\text { Pts }\end{array}$ & $\begin{array}{c}\text { Simple } \\
\text { Anatomy }\end{array}$ & $\begin{array}{l}\text { Complex } \\
\text { Anatomy }\end{array}$ & $\begin{array}{c}p \\
\text { Value }\end{array}$ \\
\hline \multicolumn{5}{|l|}{ Visual deterioration } \\
\hline Transient & $12(22.6)$ & $1(5.5)$ & $11(31.4)$ & 0.0313 \\
\hline Persisting & $2(3.8)$ & $0(0.0)$ & $2(5.7)$ & 0.5248 \\
\hline \multicolumn{5}{|l|}{ Neurologic worsening } \\
\hline Transient & $10(18.9)$ & $0(0.0)$ & $10(28.6)$ & 0.0055 \\
\hline Persisting & $4(7.5)$ & $0(0.0)$ & $4(11.4)$ & 0.5431 \\
\hline \multicolumn{5}{|l|}{ Cranial nerve palsy } \\
\hline Transient & $11(20.6)$ & $0(0.0)$ & $11(31.4)$ & 0.0094 \\
\hline Persisting & $3(5.7)$ & $0(0.0)$ & $3(8.6)$ & 0.2864 \\
\hline Change in mental status & $6(11.3)$ & $0(0.0)$ & $6(17.1)$ & 0.0436 \\
\hline Seizure & $7(13.2)$ & $2(11.1)$ & $5(14.3)$ & 0.7465 \\
\hline \multicolumn{5}{|l|}{ Endocrinological disturbance } \\
\hline SIADH & $3(5.7)$ & $0(0.0)$ & $3(8.6)$ & 0.5428 \\
\hline Diabetes insipidus & $3(5.7)$ & $0(0.0)$ & $3(8.6)$ & 0.5428 \\
\hline Panhypopituitarism & $3(5.7)$ & $0(0.0)$ & $3(8.6)$ & 0.5428 \\
\hline Infarct & $3(5.7)$ & $0(0.0)$ & $3(8.6)$ & 0.5428 \\
\hline Heubner artery injury & $3(5.7)$ & $0(0.0)$ & $3(8.6)$ & 0.5428 \\
\hline CSF leak & $1(1.9)$ & $1(5.6)$ & $0(0.0)$ & 0.3396 \\
\hline Anosmia & $1(1.9)$ & $0(0.0)$ & $1(2.9)$ & 0.47 \\
\hline Infection & $0(0.0)$ & $0(0.0)$ & $0(0.0)$ & 1.000 \\
\hline Hydrocephalus & $0(0.0)$ & $0(0.0)$ & $0(0.0)$ & 1.000 \\
\hline Recurrence & $7(13.2)$ & $2(11.1)$ & $5(14.3)$ & 0.7465 \\
\hline Mortality & $0(0.0)$ & $0(0.0)$ & $0(0.0)$ & 1.000 \\
\hline $\begin{array}{l}\text { Total persisting complica- } \\
\text { tions at last follow-up }\end{array}$ & $15(28.3)$ & $2(11.1)$ & 13 (37.1) & 0.0498 \\
\hline \multicolumn{5}{|l|}{ Length of stay, days } \\
\hline Median & & 4.5 & 6.0 & 0.0442 \\
\hline Range & & $3-16$ & $3-53$ & \\
\hline
\end{tabular}

SIADH = syndrome of inappropriate antidiuretic hormone secretion.

* Values are presented as the number of patients (\%) unless noted otherwise. preserved following craniotomy. There were a total of 7 recurrences that required additional resection and radiotherapy. The average length of stay was 10.9 days (range 3-53 days, mode 5), and there were no differences between the 2 groups except for the shorter length of stay in the patient group with the favorable anatomy (4.5 vs 6.0 days; $p=0.0442$ ). The clinical outcome results are tabulated in Table 5.

We attempted to account for overall transient and persisting complications, as the majority of new neurological deficits that the patients experienced immediately during the postoperative period had resolved by 1 year (e.g., cranial nerve palsy). By treating each persisting complication as a discrete event, we documented our overall complication rate as $28.3 \%$ in our series, which was significantly more common in the patients with complex anatomy $(11.1 \%$ vs $37.1 \%$; $p=0.0498)$ (Table 5).

\section{Evaluation of Patient Quality of Life}

Patient self-reported interpretation of functional health and well-being was recorded using SF-36 scores. On this scale of $0-100$, the lower the score, the higher the disability, and vice versa. The net change in postoperative score from preoperative score was investigated. When available, these were obtained from patients preoperatively, and postoperatively at the first (6 weeks) and second (3 months) visits. Six patients in the favorable anatomy group and 10 in the complex anatomy group did not fill out their surveys. There was a nonsignificant trend to better overall self-interpretation of health in the unfavorable anatomy group (58 vs $67 ; \mathrm{p}=0.1510$ ), and patients with smaller, easily accessible tumors thought their overall conditions improved when postoperative scores were compared $(\Delta$ SF-36 +16.6 vs $-8.4 ; p=0.0045)$ (Table 6 and Fig. 1$)$.

\section{Discussion}

Over the past several decades, anterior skull base surgery has undergone significant evolution in terms of techniques and operative approaches. The operating microscope has greatly improved surgical outcomes, and the development of endoscopic techniques has created options for both surgeons and patients. With hypothetically shorter hospital stays, minimal brain retraction, and potential for improvements in preserved visual function, endoscopic endonasal anterior skull base surgery has recently been in the spotlight as a viable alternative for microsurgical resection. When new surgical techniques emerge, a comparison against the gold standard must be made to evaluate their effectiveness. Unfortunately, in historical series of perisellar meningiomas, authors have included tumors of various sizes with multiple degrees of

TABLE 6. Quality of life outcomes for 53 patients with perisellar meningiomas

\begin{tabular}{lccc}
\hline SF-36 Score & Simple Anatomy & Complex Anatomy & p Value \\
\hline Preop & 58 & 67 & 0.1510 \\
\hline Postop & 67 & 60.1 & 0.4072 \\
\hline Difference & 16.6 & -8.4 & 0.0045 \\
\hline
\end{tabular}




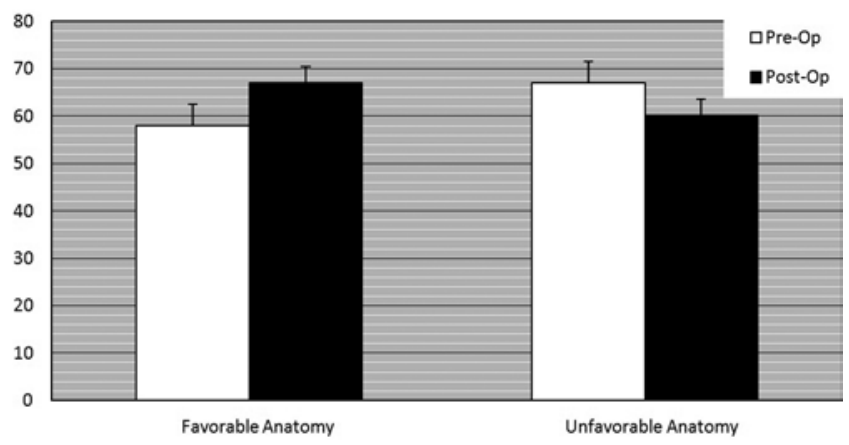

FIG. 1. Comparison of pre- and postoperative QoL outcomes between simple and complex anatomy groups for 53 patients with perisellar meningioma $(p=0.0045)$. The numbers on the $y$-axis represent SF-36 scores.

vascular encasement and optic canal involvement, all of which are variables that affect the challenge presented to the surgeon in dissection. Historical series are not stratified according to tumor anatomy, which makes the comparison of endoscopic resection of perisellar meningiomas that do not invade the optic canal and that have no vascular encasement, for example, with those that have a complex anatomy unfair.

\section{Surgical Options}

Although the subfrontal and pterional approaches remain the most common traditional methods for resection of perisellar meningiomas, the endoscopic endonasal surgical technique has started to become a viable alternative for certain tumors. ${ }^{19}$ The classic microsurgical approaches have sets of possible additional modifications to extend and adjust the exposure necessary to achieve GTR. Both the subfrontal and pterional approaches have their own advantages as well as limitations. The subfrontal approach is ideal for visualizing both sides of the tumor as well as for gaining adequate access to vital vascular structures and both optic canals. This is, however, done at the expense of frontal lobe retraction, the possibility of venous stasis in the superior sagittal sinus, more difficulty preserving olfaction, and challenges in resecting the intrasellar component of the tumor. The pterional approach allows for the minimization of brain retraction as well as for early access to ipsilateral optic nerve/internal carotid artery, at the expense of difficulty in visualizing the contralateral side of the tumor as well as challenges with resection of the intrasellar component of the lesion. .,24 $^{2}$

In our series, the pterional craniotomy with orbital osteotomy was used as the primary microsurgical approach. This was unilateral depending on the side with the worse vision, as determined preoperatively by a neuroophthalmologist. Additionally, we performed an extradural decompression of the optic canal and resected the clinoid. Early falciform ligament and proximal optic nerve sheath splitting was done prior to removal of the tumor, to minimize the surgical trauma to the optic nerve in attempts to preserve visual acuity. We attribute our higher rates of visual preservation $(96.6 \%)$ to this approach.

The Pittsburgh group recently published their experience with the endonasal resection of suprasellar meningio- mas, with favorable outcomes and preservation of visual acuity. ${ }^{19}$ In that study, Koutourousiou et al. report an $85.7 \%$ rate of visual improvement after endoscopic endonasal surgery for perisellar meningiomas. They attribute this to the early optic canal decompression through the inferiorto-superior trajectory as well as to removal of the lesions without significant manipulation of the optic nerves/chiasm, because minimizing the latter has been proven to affect visual outcomes in the transcranial literature. ${ }^{1,19,21}$ The mean tumor size removed endoscopically, however, was $2.3 \mathrm{~cm}$ (range $0.7-5.2 \mathrm{~cm}$ ), and tumor size has been implicated in visual acuity outcomes, with removal of those lesions that are $\geq 2.5 \mathrm{~cm}$ in coronal diameter resulting in worse visual acuity. ${ }^{25}$ Consequently, we were able to demonstrate that in our simple anatomy cohort, the visual outcomes were better than for those with complex anatomy, and overall the entire group had comparatively favorable visual preservation rates on follow-up.

\section{Tumor Group Selection}

Each of the tumors selected in our series was assessed by the senior author, who, based on its anatomy, determined whether a lesion would be suited for endoscopic resection (simple anatomy). The senior author has experience with both resection techniques, albeit more experience with microsurgical resection for tumors in this location. Characteristics that influenced selection criteria included tumor size, vascular encasement, optic canal involvement, and tumor shape (Table 3). As expected, those patients with smaller lesions without vascular encasement and limited lateral extension had better surgical outcomes. Although we were unable to establish the exact threshold for the maximal coronal size of the tumor that would represent a decision cutoff for one surgical approach over the other, we would suggest that surgeon experience guide decision making. This subset allows for creation of a group that can be used as a baseline for comparison in future endoscopic procedures, because historically, surgical cohorts have included perisellar meningiomas with various sizes, degrees of vascular encasement, and extent of optic canal involvement. As expected, our second cohort with complex anatomy had worse surgical outcomes. In essence, these represent 2 separate entities and should be assessed as such when deciding on a treatment modality for the patients.

\section{Surgical Outcomes}

\section{Gross-Total Resection}

Gross-total resection remains the main goal of meningioma surgery, which should always be balanced against the potential risk of complications, patient tolerance for surgery, and patient preference. Evaluation of GTR and degree of resection among the published series is not always straightforward because of different definitions of complete resection. ${ }^{6,12,22,24}$ Inconsistencies do exist in the literature, with both Fahlbusch and Schott, and Jallo and Benjamin, reporting resection rates without postoperative MRI in every case, and without association with the Simpson grade..$^{12,15}$ Other series have reported the Simpson grade in their evaluations. ${ }^{6,22}$ Ultimately, the categorization of Simpson grade removal of perisellar meningiomas 
when referring to a degree of resection is challenging because complete resection of affected dura mater may be impossible in some cases. Such is one of the potential advantages of endoscopic surgery with the inferior-posterior trajectory that would allow for early access to dural attachment in small tumors with no lateral extension. ${ }^{19}$ This must always be balanced against the risk of CSF leakage and potential for infection. We do think that in some cases lateral extension and dural tails can also be resected through a craniotomy approach, which would be more difficult endoscopically.

Traditionally, the removal of perisellar meningiomas endoscopically has resulted in a lower rate of resection when compared with open surgery, as recently demonstrated by a meta-analysis by Komotar et al. ${ }^{18}$ Tumor size, lateral extent of the lesion, interaction with the arachnoid plane, multilobular tumor configuration, vascular encasement, and sellar invasion are all factors that will limit tumor removal regardless of the surgical approach. ${ }^{6,12,19,22,24}$ Tumor size has clearly been correlated with better overall outcome not only in GTR, but also in patient morbidity. ${ }^{12,24}$ The lateral extent of the lesions will present a significant challenge to any endoscopic approach, because those lesions originating from the anterior clinoid are less accessible with the endoscope. As such, those lesions would be best suited for a transcranial approach. Additionally, given the novelty and the learning curve of the extended endonasal endoscopic surgical approach, the experience of the multidisciplinary surgical team will play a large role in the success of the resection of these tumors. Koutourousiou et al. demonstrated that with the exclusion of their first set of cases, GTR rates progressively improved, although we prefer to include all surgical cases in the cohort analysis. ${ }^{19}$

\section{Visual Outcome}

The burden of optic canal invasion and the extent of vascular encasement are 2 factors that affect the technical complexity of perisellar meningioma resection. , $^{6,10,21,22}$ Lack of optic canal invasion was one of the factors that weighed heavily in determining whether a lesion would be accessible for endoscopic resection; with an endoscopic approach, one can only effectively decompress the inferior, medial, and lateral borders of the canal $\left(270^{\circ}\right){ }^{19,20}$

As shown in Table 4, the interim visual outcomes at 6 months demonstrated a greater improvement in the group with simple anatomy. Although $38.5 \%$ of individuals with complex anatomy experienced interim worsening of vision, these were primarily transient effects. Ultimately, no patient with simple anatomy experienced any permanent visual loss, and only 2 patients $(5.7 \%)$ with complex anatomy experienced persisting visual deterioration. These excellent visual outcomes are among the highest reported in the literature. Furthermore, they do not only represent subjective visual improvement as reported by patients, because vision had been documented by objective postoperative visual testing by a neuroophthalmologist. We attribute our outcomes to several factors, including the frontotemporal craniotomy with orbital osteotomy approach, extradural decompression of the optic canal with resection of the clinoid, and the early falciform ligament and proximal optic sheath splitting prior to removal of the tumor. This approach allows for additional space within the field of view to enable manipulation of the tumor while minimizing manipulation of the optic apparatus.

There is potential for minimization of traction on the optic nerves/chiasm and ability to remove the tumors with the endoscopic endonasal approach. Koutourousiou et al. were able to achieve an $85.7 \%$ rate of visual improvement that they attribute to the inferior-to-superior trajectory of the endoscope. ${ }^{1,5,10,11,17,19,26}$ This ability to remove the medial wall of the optic canal beyond the optic strut can be safely achieved by extended endoscopic surgery. The challenge with craniotomy is because there are difficulties with medial and inferomedial aspects with the optic canal where the tumor often invades; ${ }^{21}$ this is minimized with the technique used by the senior author.

Mounting evidence suggests that early optic canal decompression is crucial for visual preservation. This can be accomplished with both endoscopic and craniotomy approaches. Proponents of the endoscope would suggest that the medial and inferomedial early decompression is more easily achieved with that approach. ${ }^{5,8,11,17-20}$ However, other authors have documented that visual outcome is affected by tumor size $(<2.5 \mathrm{~cm})$, and additional factors such as duration of preoperative visual symptoms, degree of preoperative visual impairment, and patient age have been correlated with postoperative visual outcome. ${ }^{23,25}$ We were able to further correlate such factors in our group. With careful patient selection, visual outcomes with small tumors that do not encase vasculature or involve the optic canals can be comparable to those of endoscopic resection. Those lesions that are large with complex anatomy seem likely to have poor visual outcomes regardless of the surgical approach.

\section{Rate of Recurrences}

The average follow-up in our study was 37.3 months (range 10-120 months), with a slightly longer follow-up in the group with appropriate anatomy for endoscopic resection (43.2 months, range 10-120 months) compared with tumors with complex anatomy (34.2 months, range 12-84 months). We acknowledge that the follow-up for our series is on the lower end of length of follow-up when compared with other papers that examined perisellar meningiomas (range 38-125 months). ${ }^{7,12,19}$ Seven patients (13.2\%) experienced recurrences on high-resolution MRI but only 6 required additional treatment; 2 patients required a repeat craniotomy, and 4 patients underwent radiotherapy. At our institution, the practice is to follow patients indefinitely with routine MRI scans at regular yearly intervals for the first 3 years, then at 5-year intervals, whereas those patients who have atypical meningioma pathology or residual tumor are followed yearly. The median number of follow-up postoperative MRI scans was 7 in each cohort.

\section{Complication Rates}

One of the most challenging aspects of the resection of perisellar meningiomas is the preservation of the patient's visual function. The intraoperative manipulation of intracranial vasculature as well as the optic nerves/chiasm puts this in jeopardy. In our study, we found a transient worsening of vision in $22.6 \%$ of patients ( 12 of 53), the majority of whom were those with lesions that had complex anatomy. 
Fortunately, by 1-year follow-up, the majority of these had resolved, yielding only a $3.8 \%$ ( 2 of 53 patients) rate of permanent visual deterioration, all in patients with complicated tumor anatomy only. In the literature, this ranges from $10 \%$ to $30 \%$ for the same approach..$^{12,15,21}$ One of the advantages of the extended endoscopic approach used by Koutourousiou et al. is the expected lower rate of visual deterioration, reported at $3.6 \% .{ }^{19}$ This is attributed to the inferior-to-superior trajectory of the approach, which hypothetically spares traumatic microdissection of the optic nerves. We attribute our low rate of permanent visual deterioration to the decompression of the optic canal as described, which allowed us some ability to manipulate the tumor while avoiding damage to the optic nerve.

A CSF leak is one of the complications that will be avoided by the microsurgical approach. Although it can occur through the frontal sinus and drilling out of any hyperostotic bone during a craniotomy, the rate of CSF leaks has varied. It was $4 \%$ in a series published by Symon and Rosenstein with the subfrontal approach, while the study by Nakamura et al. found a similar rate (4.2\%) with mixed approaches, and Fahlbusch and Schott had a rate of $6.4 \%$ with their pterional approach..$^{12,22,24}$ In our study, only 1 patient had a CSF leak that required interventiona patient who had a recurrent lesion and required surgical repair of the leak via an endoscopic approach. Overall, an advantage of either the subfrontal or pterional approaches is the lower rate of CSF leaks compared with endoscopic resection, which was $25.3 \%$ in the Koutourousiou series, and in comparable series with the same approach for craniopharyngiomas the rate was $20.3 \% .{ }^{20} \mathrm{~A}$ recent literature search found an overall rate of $31.6 \%$ among 3 studies that examined endoscopic resection of anterior skull base meningiomas. ${ }^{18}$ These CSF leaks seldom lead to significant morbidity, such as meningitis (incidence 2\%), and the use of the vascularized nasoseptal flap for reconstruction has decreased the CSF leak rate from endonasal approaches to $15 \%{ }^{17,29}$ Ultimately, this is a complication that plagues endonasal techniques, the occurrence of which adds significant morbidity if repeat surgical repair is required.

Low rates of endocrinological disturbances (syndrome of inappropriate antidiuretic hormone secretion, diabetes insipidus, and panhypopituitarism), hydrocephalus, and respiratory and cardiovascular events were seen in our patients (Table 5). New-onset seizures occurred in $13.2 \%$ (7 of 53) of patients in our series. Heubner artery injury was seen in $5.7 \%$ ( 3 of 53) patients. Both the seizures and the vascular injuries are described in the literature, and can cause significant morbidity and are sometimes even fatal. ${ }^{14}$ Anosmia is a significant complication following endoscopic surgery. Although no concrete numbers can be found for perisellar meningiomas, a recent literature review found disturbances of olfaction to be reported at $26.7 \%$, with nasal crusting (50.8\%), nasal discharge (40.4\%), and airflow blockage $(40.1 \%)$ being other common sinonasal morbidities. ${ }^{2}$ We saw an exceedingly low rate of documented anosmia in our series, with 1 patient (1.9\%) experiencing a permanent loss of smell postoperatively.

In the postmicroscope era, mortality following craniotomy for suprasellar meningiomas has dropped to $<3 \% .^{24}$ In our series, there were no deaths. Careful patient selection should still be a predominant force in the decision process to ensure that those who undergo such procedures are medically fit to tolerate the intervention. Arguably, it is difficult to establish the exact rate of clinically significant and meaningful complications after craniotomy for perisellar meningiomas. We attempted to calculate this value as accurately as possible, including persisting disabling deficits at final follow-up. The overall rate of these were $28.3 \%$ (15 of 53 patients), with 2 (3.8\%) patients experiencing such symptoms in the simple anatomy group and $13(24.5 \%)$ in the complex anatomy group. Comparison against the literature is challenging, because documentation has been sparse. It is difficult to determine whether a particular complication described was persisting or temporary. We counted each persisting complication as a separate event, and our rate appears to be on the lower end when compared to the literature (Table 7). When we analyzed the largest studies reported in the recent literature, we found the overall complication rate for patients with perisellar meningiomas to be $5.9 \%-62.4 \%$, but whether these are permanent or temporary, or counted as discrete events, is challenging to interpret.

\section{Quality of Life}

Patient-perceived quality of life (QoL) outcomes were

TABLE 7. Recent studies showing visual outcomes, GTR, and postoperative complications in patients with perisellar meningiomas

\begin{tabular}{|c|c|c|c|c|c|c|}
\hline Authors \& Year & No. of Pts & SA & $\%$ GTR & $\%$ VP & $\%$ Mortality & $\mathrm{TC}^{*}$ \\
\hline Symon \& Rosenstein, 1984 & 101 & Subfrontal & 78.2 & 75.8 & 5.9 & $63(62.4)$ \\
\hline Ciric \& Rosenblatt, 2001 & 24 & Frontotemporoparietal & 66.7 & & 0.0 & $10(41.7)$ \\
\hline Goel et al., 2002 & 70 & Unilateral subfrontal & 84.3 & 90.0 & 2.9 & $20(28.6)$ \\
\hline Fahlbusch \& Schott, 2002 & 47 & Pterional & 97.9 & 80.0 & 0.0 & $24(51.1)$ \\
\hline Schick \& Hassler, 2005 & 53 & Pterional & 90.6 & 87.5 & 3.7 & $20(37.7)$ \\
\hline Nakamura et al., 2006 & 72 & Mixed & 91.7 & 67.9 & 2.8 & $21(29.2)$ \\
\hline Mahmoud et al., 2010 & 58 & Supraorbital & 87.9 & 92 & 1.7 & $29(50.0)$ \\
\hline Chokyu et al., 2011 & 34 & Subfrontal & 79.4 & 100 & 0.0 & $2(5.9)$ \\
\hline Koutourousiou et al., 2014 & 75 & Endoscopic & 81.4 & 96.4 & 1.3 & $36(48.0)$ \\
\hline Present study & 53 & Pterional & 91.4 & 96.6 & 0.0 & $15(28.3)$ \\
\hline
\end{tabular}

$\mathrm{SA}=$ surgical approach; $\mathrm{TC}=$ total persisting complications at last follow-up; $\mathrm{VP}=$ visual preservation.

* Values are presented as the number of patients (\%). 
recorded by the validated tool of the SF-36 both during the preoperative visit and postoperatively. ${ }^{27,28}$ To date, there are no studies including patient QoL assessments when discussing resection of perisellar meningiomas. Unfortunately, we were not able to collect and tabulate SF-36 scores from all of the patients due to patient refusal, lost forms, or unknown reasons; as such, our response rate was $69.8 \%$ (37 of 53 patients). Nonetheless, although it appears that the patients with simple anatomy had a worse preoperative perception of their QoL (58 vs 67), the overall change postoperatively was toward a trend of an improvement in QoL (+16.6 vs -8.4; $\mathrm{p}=0.0045$ ) (Fig. 1). The patients with complex lesions overall had a longer hospital stay, a higher rate of complications, and worse visual outcomes given the nature of the anatomy of their tumors and the complexity of the surgery. It stands to reason that these experiences would negatively impact the interpretation of their QoL.

Ultimately, more succinct data are needed to reliably establish pre- and postoperative QoL. However, our data provide important insight into how patients with perisellar lesions fare after open craniotomy and microsurgical resection of their tumors, which is a unique aspect in the current literature.

\section{Limitations of the Study}

This is a single-center, retrospective chart review. The strength of our study is limited because it represents a single surgeon's experience and thus it may not be generalizable. But this is true of most of the literature on this topic. There is perhaps selection/referral bias, and it is a relatively small cohort. Given the relative novelty of the extended endonasal surgery at our center, we were unable to include any such cases in this write-up. The determination of whether a lesion was suitable for endoscopic resection (simple vs complex anatomy) and subsequent allocation to either study arm was also determined on a subjective basis, while keeping literature considerations in mind.

\section{Conclusions}

Microsurgical resection of perisellar meningiomas remains the gold standard treatment, but technological advancements have allowed extended endoscopic surgery to emerge as a viable alternative. It is less externally invasive and is a more direct route to the perisellar area, which allows an ideal access to midline anterior skull base lesions. Access to the tumors inferiorly allows early tumor devascularization and resection of dural attachments prior to tumor debulking. Hypothetically, there is the opportunity for preservation of optic apparatus vascularization and minimization of optic nerve manipulation. Koutourousiou et al. have demonstrated that endoscopic endonasal surgery is safe and efficient. ${ }^{19}$ The increased CSF leak rates continue to be a challenge, but with new techniques such as the vascularized nasoseptal flap with skull base reconstruction, these rates will hopefully decrease.

When presenting treatment options to the patient who has a perisellar meningioma, it is important to list the risks and benefits of each procedure. Historically, craniotomy series, including various perisellar lesions, were used as a comparison for endoscopic surgery. These included both small, compact lesions without vascular encasement that would be appropriate for endoscopic resection, and complex lesions of significant size and mass effect that would not be considered by most surgeons for resection with an endoscope. As a result, the comparison would not be a fair one. With this study, we have separated perisellar lesions into 2 categories in the hope of providing a cohort for comparison of future endoscopic procedures in our center. The adoption of new surgical techniques needs careful evaluation. In our center, with results achieved for these tumors (whether with simple or complex anatomy) through an open procedure, careful thought is required when considering endoscopic approaches. We have illustrated that complex cases have higher complication rates and lower rates of resection. Although this seems self-explanatory, it has not been previously documented in the literature. The cohort with simple anatomy represents a more accurate comparison for future endoscopic series in our facility.

\section{References}

1. Attia M, Kandasamy J, Jakimovski D, Bedrosian J, Alimi M, Lee DL, et al: The importance and timing of optic canal exploration and decompression during endoscopic endonasal resection of tuberculum sella and planum sphenoidale meningiomas. Neurosurgery 71 (Suppl Operative):58-67, 2012

2. Awad AJ, Mohyeldin A, El-Sayed IH, Aghi MK: Sinonasal morbidity following endoscopic endonasal skull base surgery. Clin Neurol Neurosurg 130:162-167, 2015

3. Benjamini Y, Hochberg Y: Controlling the false discovery rate: a practical and powerful approach to multiple testing. $\mathbf{J}$ R Stat Soc B 57:289-300, 1995

4. Campero A, Martins C, Socolovsky M, Torino R, Yasuda A, Domitrovic L, et al: Three-piece orbitozygomatic approach. Neurosurgery 66 (3 Suppl Operative):E119-E120, 2010

5. Cappabianca P, Cavallo LM, Esposito F, De Divitiis O, Messina A, De Divitiis E: Extended endoscopic endonasal approach to the midline skull base: the evolving role of transsphenoidal surgery. Adv Tech Stand Neurosurg 33:151-199, 2008

6. Chokyu I, Goto T, Ishibashi K, Nagata T, Ohata K: Bilateral subfrontal approach for tuberculum sellae meningiomas in long-term postoperative visual outcome. J Neurosurg 115:802-810, 2011

7. Ciric I, Rosenblatt S: Suprasellar meningiomas. Neurosurgery 49:1372-1377, 2001

8. Cook SW, Smith Z, Kelly DF: Endonasal transsphenoidal removal of tuberculum sellae meningiomas: technical note. Neurosurgery 55:239-246, 2004

9. Couldwell WT, Weiss MH, Rabb C, Liu JK, Apfelbaum RI, Fukushima T: Variations on the standard transsphenoidal approach to the sellar region, with emphasis on the extended approaches and parasellar approaches: surgical experience in 105 cases. Neurosurgery 55:539-550, 2004

10. de Divitiis E, Cavallo LM, Esposito F, Stella L, Messina A: Extended endoscopic transsphenoidal approach for tuberculum sellae meningiomas. Neurosurgery 61 (5 Suppl 2):229238, 2007

11. Dehdashti AR, Ganna A, Witterick I, Gentili F: Expanded endoscopic endonasal approach for anterior cranial base and suprasellar lesions: indications and limitations. Neurosurgery 64:677-689, 2009

12. Fahlbusch R, Schott W: Pterional surgery of meningiomas of the tuberculum sellae and planum sphenoidale: surgical results with special consideration of ophthalmological and endocrinological outcomes. J Neurosurg 96:235-243, 2002

13. Glickman ME, Rao SR, Schultz MR: False discovery rate 
control is a recommended alternative to Bonferroni-type adjustments in health studies. J Clin Epidemiol 67:850-857, 2014

14. Goel A, Muzumdar D, Desai KI: Tuberculum sellae meningioma: a report on management on the basis of a surgical experience with 70 patients. Neurosurgery 51:1358-1364, 2002

15. Jallo GI, Benjamin V: Tuberculum sellae meningiomas: microsurgical anatomy and surgical technique. Neurosurgery 51:1432-1440, 2002

16. Kadis GN, Mount LA, Ganti SR: The importance of early diagnosis and treatment of the meningiomas of the planum sphenoidale and tuberculum sellae: a retrospective study of 105 cases. Surg Neurol 12:367-371, 1979

17. Kassam AB, Thomas A, Carrau RL, Snyderman CH, Vescan A, Prevedello D, et al: Endoscopic reconstruction of the cranial base using a pedicled nasoseptal flap. Neurosurgery 63 (1 Suppl 1):ONS44-ONS53, 2008

18. Komotar RJ, Starke RM, Raper DM, Anand VK, Schwartz TH: Endoscopic endonasal versus open transcranial resection of anterior midline skull base meningiomas. World Neurosurg 77:713-724, 2012

19. Koutourousiou M, Fernandez-Miranda JC, Stefko ST, Wang EW, Snyderman CH, Gardner PA: Endoscopic endonasal surgery for suprasellar meningiomas: experience with 75 patients. J Neurosurg 120:1326-1339, 2014

20. Koutourousiou M, Gardner PA, Fernandez-Miranda JC, Tyler-Kabara EC, Wang EW, Snyderman CH: Endoscopic endonasal surgery for craniopharyngiomas: surgical outcome in 64 patients. J Neurosurg 119:1194-1207, 2013

21. Mahmoud M, Nader R, Al-Mefty O: Optic canal involvement in tuberculum sellae meningiomas: influence on approach, recurrence, and visual recovery. Neurosurgery 67 (3 Suppl Operative):ons108-ons119, 2010

22. Nakamura M, Roser F, Struck M, Vorkapic P, Samii M: Tuberculum sellae meningiomas: clinical outcome considering different surgical approaches. Neurosurgery 59:1019-1029, 2006

23. Schick U, Hassler W: Surgical management of tuberculum sellae meningiomas: involvement of the optic canal and visual outcome. J Neurol Neurosurg Psychiatry 76:977-983, 2005

24. Symon L, Rosenstein J: Surgical management of suprasellar meningioma. Part 1: The influence of tumor size, duration of symptoms, and microsurgery on surgical outcome in 101 consecutive cases. J Neurosurg 61:633-641, 1984

25. Taha AN, Erkmen K, Dunn IF, Pravdenkova S, Al-Mefty O: Meningiomas involving the optic canal: pattern of involve- ment and implications for surgical technique. Neurosurg Focus 30(5):E12, 2011

26. Van Gompel JJ, Frank G, Pasquini E, Zoli M, Hoover J, Lanzino G: Expanded endonasal endoscopic resection of anterior fossa meningiomas: report of 13 cases and meta-analysis of the literature. Neurosurg Focus 30(5):E15, 2011

27. Ware JE Jr, Sherbourne CD: The MOS 36-Item Short-Form Health Survey (SF-36). I. Conceptual framework and item selection. Med Care 30:473-483, 1992

28. Ware JE Jr, Snow KK, Kosinski M, Gandek B: SF-36 Health Survey Manual and Interpretation Guide. Boston: New England Medical Center, 1993

29. Zanation AM, Carrau RL, Snyderman CH, Germanwala AV, Gardner PA, Prevedello DM, et al: Nasoseptal flap reconstruction of high flow intraoperative cerebral spinal fluid leaks during endoscopic skull base surgery. Am J Rhinol Allergy 23:518-521, 2009

\section{Disclosures}

The authors report no conflict of interest concerning the materials or methods used in this study or the findings specified in this paper.

\section{Author Contributions}

Conception and design: Makarenko, Akagami. Acquisition of data: Makarenko. Analysis and interpretation of data: all authors. Drafting the article: Makarenko, Carreras. Critically revising the article: all authors. Reviewed submitted version of manuscript: all authors. Approved the final version of the manuscript on behalf of all authors: Makarenko. Statistical analysis: Carreras. Administrative/technical/material support: Carreras. Study supervision: Makarenko, Akagami. Primary investigator: Akagami.

\section{Supplemental Information}

Previous Presentations

Portions of this work were presented in abstract form and as proceedings at the 25th Annual Meeting, International Conference on Skull Base Surgery, North American Skull Base Society, Tampa Bay, Florida, February 20, 2015.

\section{Correspondence}

Serge Makarenko, Neurosurgery, Vancouver General Hospital, 899 West 12th Ave., Vancouver, BC V5Z 1M9, Canada. email: smakarenko@gmail.com. 